INDO GLOBAL JOURNAL OF

PHARMACEUTICAL SCIENCES

ISSN 2249- 1023

\title{
Transdermal Drug Delivery System
}

\author{
Mandeep Kaur heir *, Sachin Sharma \\ Sri Sai College of Pharmacy, Manawala, Amritsar-143115, Punjab, India
}

Address for Correspondence: Mandeep Kaur heir; heirmandeepkaur@gmail.com

\section{Received: \\ 01.03.2019 \\ Accepted: \\ 25.03.2019 \\ Keywords \\ Transdermal; \\ Pharmacological; \\ Systemic.}

\begin{abstract}
Transdermal drug delivery system can deliver the drugs through the skin portal to systemic circulation at a predetermined rate and maintain clinically the effective concentrations over a prolonged period of time. Transdermal patch is a medicated adhesive patch that is placed on the skin to deliver a specific dose of medication through the skin and into the bloodstream. Often, this promotes healing to an injured area of the body. The advantage of a transdermal drug delivery route over other types of medication delivery such as oral, topical, intravenous, intramuscular, etc. is that the patch provides a controlled release of the medication into the patient. These system offer pharmacological advantages over the oral route and improved patient acceptability and compliance. Transdermal drug delivery systems are pharmaceutical preparations, intended to be applied to the unbroken skin in order to deliver the active ingredient to the systemic circulation after passing through the skin barrier. They are applied with aim of cleaning and protecting the skin. These devices are easy to apply and also easily removed from the skin. (C) 2019 iGlobal Research and Publishing Foundation. All rights reserved.
\end{abstract}

Cite this article as: Heir, M.K.; Sharma, S. Transdermal Drug Delivery System. Indo Global J. Pharm. Sci., 2019; 9(2Suppl.): 155. DOI: http://doi.org/10.35652/IGJPS.2019.92S53 .

Indo Global Journal of Pharmaceutical Sciences( ISSN 2249 1023; CODEN- IGJPAI; NLM ID: 101610675) indexed and abstracted in CrossRef (DOI Enabling), UGC CARE Journal List, EMBASE(Elsevier), National Library of Medicine (NLM) Catalog, ResearchGate, Publons, CAS (ACS), Index Copernicus, Google Scholar and many more. For further details, visit http://iglobaljournal.com

This is a special issue as an outcome of 'RAPSCON-2019' sponsored by APTI and organized by Sri Sai College of Pharmacy, Manawala, Amritsar, Punjab, India. Relaxation offered in journal format. 